\title{
Quality of Prescriptions in a Tertiary Care Hospital in South-West Nigeria
}

\author{
Joseph O. Fadare ${ }^{1 *}$, Segun Matthew Agboola ${ }^{2}$, Rachel A. Alabi ${ }^{3}$ \\ ${ }_{1}^{1}$ Department of Pharmacology, College of Medicine, Ekiti State University, Ado-Ekiti, Nigeria \\ ${ }^{2}$ Department of Family Medicine, Federal Medical Centre, Ido-Ekiti, Nigeria \\ ${ }^{3}$ Pharmacy Department, Federal Medical Centre, Ido-Ekiti, Nigeria
}

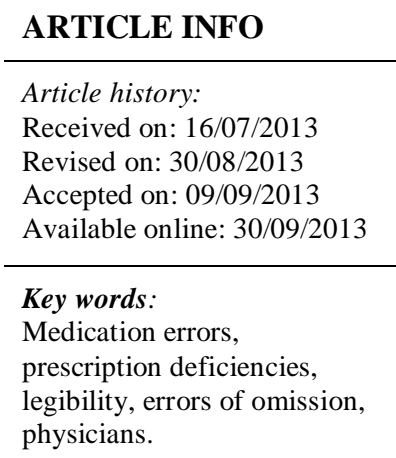

\section{INTRODUCTION}

A prescription is usually the end product of a patientdoctor encounter and its quality has significant impact on the outcome of this encounter. A prescription error has been described as "'a failure in the prescription writing process that results in a wrong instruction about one or more of the normal features of a prescription (Aronson, 2009). The essential components of a prescription include the identity of the recipient, the identity of the drug, the formulation, dose, route, timing, frequency, and duration of administration (deVries TPGM, 1994). Legibility or readability of the prescription is also an important component that may affect its quality and subsequently impact negatively on the patient (Hartel et al., 2011). The number of drugs prescribed has been shown to have its relevance when discussing the quality of prescriptions as it may impact negatively on health and economic outcomes (Rambhade et al., 2012). Prescribing by brands or generics is also another yardstick by

\footnotetext{
* Corresponding Author

Dr Joseph O. Fadare, Email: jofadare@gmail.com

Tel: +2348138048127
}

which the quality of prescriptions is measured because of availability and cost issues (Flegel, 2012). Studies from Europe, North and Central Africa have shown that issues with prescriptions remain a significant problem (Silverio and Leite, 2010, Yousif et al., 2006, Makonnen et al., 2002). Some of the reasons that have been identified include poor undergraduate and postgraduate medical training in clinical pharmacology and therapeutics, the ever increasing number of drugs, work-related factors and lack of regular audit and feedback (Heaton et al., 2008, Ross et al., 2013, Bertels et al., 2013). Prescription errors have also been identified as a cause of adverse drug reactions with potential huge health and economic consequences. In Nigeria, Oshikoya et al have described the quality of prescriptions from the children outpatients department (Oshikoya and Ojo, 2007). However, there is a gap in knowledge especially as it relates to the quality of prescriptions in the adult outpatients department. The main objective of this study was to investigate the deficiencies in prescriptions from the adult outpatients departments of a tertiary centre in Nigeria. 


\section{METHODS}

The study was carried out at the Federal Medical Centre, a healthcare facility located in Ido-Ekiti, South-West Nigeria. The centre provides secondary and tertiary level of care and is accredited for post-graduate medical training in Family Medicine, Internal Medicine, Paediatrics, Surgery, Psychiatry and Obstetrics and Gynaecology.

A cross-sectional retrospective analysis of randomly selected prescriptions from all outpatient clinics of the hospital between October 1, 2010 and March 31, 2011 was carried out. All prescriptions submitted to the central pharmacy from all outpatients' clinics of the hospital for the above mentioned months were collected by the investigators. One hundred (100) prescriptions were selected per month for five months and 102 for one month through stratified random sampling. The prescriptions were checked for the completeness of the patients' bio-data (name, age, sex, and hospital number), accuracy of drug dosage and formulation, prescribing by generic name, use of abbreviation, legibility of prescriber's writing, the name and signature of the prescriber.

The legibility of the prescribers was assessed by two doctors (one consultant and registrar) and a pharmacist using a rating scale adapted from a previous study (Akoria and Isah, 2009). Each of the assessors scored all the collected prescriptions anonymously using the rating scale. The rating scale used was an ordinal one with 0 : completely illegible 1: fairly legible, 2 : moderately legible, 3: clearly legible, 4: print quality. The mean rating score for the prescriptions was obtained by finding the average of the rating scores of the three assessors. The data retrieved was entered and descriptive analysis done using SPSS version 16 software.

\section{Ethical Consideration}

Ethical clearance for the study was obtained from the Research Ethics Committee of the hospital before the commencement of the study.

\section{RESULTS}

A total of 602 prescriptions were collected and used for analysis. All the prescriptions had patient's name and hospital numbers written. The age of the patients was recorded in 421 (69.9\%) while the non-specific term of "Adult" was used instead of specific age on the remaining prescriptions. The hospital number was indicated in $480(79.7 \%)$ while the address was present in only $323(53.7 \%)$ of the prescriptions. The duration of use was indicated in $98.8 \%$ of the collected prescription while the dosage form was present in $99.7 \%$. The route of administration was indicated correctly in 598 (99.3\%) prescriptions. The doctor's name, signature and date was indicated 587 (97.5\%), 546 (90.7\%) and $556(92.7 \%)$ respectively. The mean legibility score was 2.53 \pm 0.51 out of a possible score 4 .

Table 1 shows details of the assessors rating score. A total of 2167 medications were prescribed with a mean of $3.6 \pm 1.6$ per encounter. The minimal number of drug prescribed was one while the maximum was nine (9). Three hundred and thirteen (52\%) prescriptions had less than 4 drugs while 289 (48\%) had four or more drugs.

Table. 1: Mean scores of legibility and distribution by percentiles.

\begin{tabular}{lllll}
\hline & D1 & D2 & P1 & Summary \\
\hline No of prescriptions & 602 & 602 & 601 & 602 \\
Mean rating score & 2.64 & 2.55 & 2.40 & 2.53 \\
Median rating score & 3.0 & 3.0 & 2.0 & 2.70 \\
Percentile & & & & \\
$\mathbf{2 5}$ & 2.0 & 2.0 & 2.0 & 2.3 \\
$\mathbf{5 0}$ & 3.0 & 3.0 & 2.0 & 2.7 \\
$\mathbf{7 5}$ & 3.0 & 3.0 & 3.0 & 3.0 \\
\hline
\end{tabular}

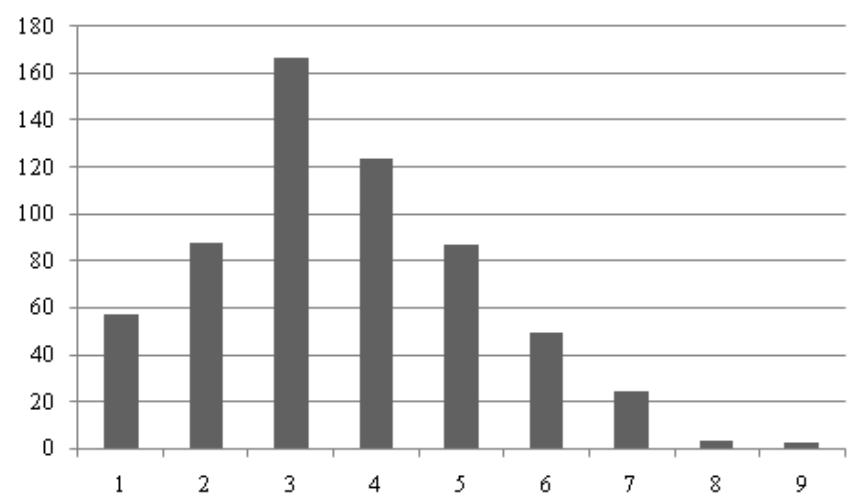

Fig. 1: The detailed breakdown of number of drugs prescribed.

Prescribing by generic name was done in $61.6 \%( \pm 30.2)$ of all drugs. The relationship between the numbers of drugs prescribed on one side and the legibility score and prescribing by generic name using Pearson's correlation was - .034 and -.032 respectively (Table 2).

Table. 2:

\begin{tabular}{llll}
\hline \multicolumn{1}{c}{$\begin{array}{c}\text { Pearson's } \\
\text { correlation }\end{array}$} & $\begin{array}{c}\text { Total Number } \\
\text { of Drugs } \\
\text { (TND) }\end{array}$ & $\begin{array}{c}\text { Percentage of } \\
\text { drugs by } \\
\text { generic (PBG) }\end{array}$ & $\begin{array}{c}\text { Mean } \\
\text { Legibility } \\
\text { Score }\end{array}$ \\
\hline TND (Sig) & 1 & $-.032(.427)$ & $-.034(.408)$ \\
PBG (Sig) & -.032 & 1 & $.158(.000)$ \\
Mean Legibility & $-.034(.408)$ & $.158(.000)$ & 1 \\
score (Sig) & & & \\
\hline
\end{tabular}

\section{DISCUSSION}

The patient identifier (name, hospital number and address) was present in $100 \%, 79.7 \%$ and $53.7 \%$ of the collected prescription respectively. In a study carried out in Sudan where three names were used, only $18.8 \%$ of prescriptions were in compliance while a Nepalese study also had $100 \%$ compliance (Yousif et al., 2006, Ansari and Neupane, 2009). The relatively low level of filling in the address of the patients may be due to the pressure of work in the outpatients departments or the fact that this information already exists in the case notes. The age of patients was written in $69.9 \%$ of the prescriptions, higher than $50 \%$ recorded in an Ethiopian study (Makonnen et al., 2002). The duration of use, dosage form and correct route of administration was indicated in $98.7 \%, 99.7 \%$ and $99.3 \%$ of the prescriptions 
respectively; these values are higher than $25.7 \%$ (for duration of use) and $87 \%$ (route of administration) recorded in previous studies (Yousif et al., 2006, Calligaris et al., 2009). Being a medico-legal document, a prescription is required to have the full name of the prescribing doctor, his/her signature and the date. In our study, the name and signature of the prescribing doctor and the date were found in $97.5 \%, 90.7 \%$ and $92.4 \%$ of the prescriptions respectively. The physicians' names were present in only $6.7 \%$ of a previously quoted Sudanese study while only $33.3 \%$ and $43.9 \%$ of prescriptions from an Italian study had the signature of the prescribers and date of encounter (Rambhade et al., 2012, Calligaris et al., 2009). The average number of medicines per prescription was $3.6 \pm 1.6$, close to the mean of $3 \pm 1.5$ obtained in a Nigerian study (Adebayo and Hussain, 2009). Similarly, the mean number of prescribed drugs found in studies from other countries was 2.3 (Sudan), 1.83 (Nepal), 2.1 (Saudi Arabia) and 2.8 (India) (Cheraghali and Idries, 2009, Das et al., 2011, Irshaid et al., 2004, Bhartiy et al., 2008). The differences in mean number of prescribed drugs in these studies may be due to prescribers training in rational use of medicines, geographical and epidemiological variation of diseases. In this study, prescribing by generic name was done in $61.6 \pm 30.2 \%$ of the prescriptions, higher than $41.9 \%$ and $42.7 \%$ found in previous Nigerian studies (Akande and Ologe, 2007, Tamuno and Fadare, 2012).

Our result was also significantly higher than that from similar Sudanese and Italian studies where generic prescribing was found in only $19.5 \%$ and $24.7 \%$ of prescriptions respectively (Yousif et al., 2006, Di Paolo et al., 2012). The influence of pharmaceutical companies on the prescribing habits of doctors may play a role in this abysmal low level of generic prescribing. Studies have shown that the influence of medical detailing has some effect on the prescribing pattern of doctors (Sondergaard et al., 2009, Lieb and Brandtonies, 2010). This upward trend in generic prescribing could contribute to a reduction in healthcare cost especially out of pocket expenses that are predominant in developing countries. This result also suggests that various intervention strategies in the area of prescriber's education in Nigeria on rational use of medicines may have started yielding positive fruits. In our study, $93.5 \%$ of all prescriptions were classified as being moderately legible to print quality with the mean legibility score of 2.53. Another Nigerian study found only $20 \%$ of the prescriptions as clearly legible while Winslow et al reported $20 \%$ of medication orders as being illegible or legible with effort (Akoria and Isah, 2008, Winslow et al., 1997). Legibility or readability of prescriptions is a very important quality as it reduces medication errors due to transcription. This type of preventable error includes dispensing of wrong dosage form, quantity or medications which may lead to significant harm of the patients. Recent studies have shown that there is indeed a high level of documentation errors in handwritten prescriptions and a comparison of the legibility between printed and written prescriptions revealed a statistically significant difference (Hartel et al., 2011, Yousif et al., 2011). Strategies that have been implemented to improve legibility of prescriptions include the use of a computerized prescription order entry (CPOE) system and the use of computer -aided prescribing (Conroy et al., 2007, Mirco et al., 2005). These interventions have clearly shown a reduction in risk of prescribing errors in several studies (van Rosse et al., 2009, Jayawardena et al., 2007). Prescription writing in plain English without the use of abbreviations and Latin are other strategies that may improve the legibility of prescriptions and reduce prescribing errors (Benjamin, 2003).

\section{CONCLUSION}

The findings of our study show that there is a need for improvement in the quality of prescription written by Nigerian doctors. Training of prescribers to focus on the little details of prescription writing and adoption of computer -aided prescribing system would go a long way in achieving this objective.

\section{STUDY LIMITATIONS}

The major limitation of this study is the subjectivity of assessing the legibility of the prescriptions. This was addressed through the use of validated instrument by multiple assessors. Also being a retrospective study, it was not possible to know the context of the prescribing encounters.

\section{REFERENCES}

ADEBAYO, E. T. \& HUSSAIN, N. A. A baseline study of drug prescribing practices in a Nigerian military hospital. Niger J Clin Pract, 2009; 12, 268-72.

AKANDE, T. M. \& OLOGE, M. O. Prescription pattern at a secondary health care facility in Ilorin, Nigeria. Ann Afr Med, 2007; 6, $186-9$.

AKORIA, O. A. \& ISAH, A. O. Prescription writing in public and private hospitals in Benin City, Nigeria: the effects of an educational intervention. Can J Clin Pharmacol, 2008; 15, e295-305.

AKORIA, O. A. \& ISAH, A. O.. A Comparison of Two Instruments for the Assessment of Legibility of Prescriptions in a Developing Country. Tropical Journal of Pharmaceutical Research, 2009; 8(6): 485-489.

ANSARI, M. \& NEUPANE, D. Study on determination of errors in prescription writing: A semi-electronic perspective. Kathmandu Univ Med J (KUMJ), 2009; 7, 238-41.

ARONSON, J. K. Medication errors: definitions and classification. Br J Clin Pharmacol, 2009; 67, 599-604.

BENJAMIN, D. M. Reducing medication errors and increasing patient safety: case studies in clinical pharmacology. J Clin Pharmacol, 2003; 43, 768-83.

BERTELS, J., ALMOUDARIS, A. M., CORTOOS, P. J., JACKLIN, A. \& FRANKLIN, B. D. Feedback on prescribing errors to junior doctors: exploring views, problems and preferred methods. Int $J$ Clin Pharm, 2013; 35, 332-8.

BHARTIY, S. S., SHINDE, M., NANDESHWAR, S. \& TIWARI, S. C. Pattern of prescribing practices in the Madhya Pradesh, India. Kathmandu Univ Med J (KUMJ), 2008; 6, 55-9.

CALLIGARIS, L., PANZERA, A., ARNOLDO, L., LONDERO, C., QUATTRIN, R., TRONCON, M. G. \& BRUSAFERRO, $\mathrm{S}$. Errors and omissions in hospital prescriptions: a survey of prescription writing in a hospital. BMC Clin Pharmacol, 2009; 9, 9.

CHERAGHALI, A. M. \& IDRIES, A. M. Availability, affordability, and prescribing pattern of medicines in Sudan. Pharm World Sci, 2009; 31, 209-15.

CONROY, S., SWEIS, D., PLANNER, C., YEUNG, V., COLLIER, J., HAINES, L. \& WONG, I. C. Interventions to reduce dosing 
errors in children: a systematic review of the literature. Drug Saf, 2007; 30, 1111-25.

DAS, P., DAS, B. P., RAUNIAR, G. P., ROY, R. K. \& SHARMA, S. K. Drug utilization pattern and effectiveness analysis in diabetes mellitus at a tertiary care centre in eastern Nepal. Indian J Physiol Pharmacol, 2011; 55, 272-80.

DE VRIES TPGM, H. R., HOGERZEIL HV, FRESLE DA 1994. Guide to good prescribing. In: ORGANIZATION, W. H. (ed.). Geneva.

DI PAOLO, E. R., GEHRI, M., OUEDRAOGO-RUCHET, L., SIBAILLY, G., LUTZ, N. \& PANNATIER, A. Outpatient prescriptions practice and writing quality in a paediatric university hospital. Swiss Med Wkly, 2012; 142, w13564.

FLEGEL, K. The adverse effects of brand-name drug prescribing. CMAJ, 2012; 184, 616.

HARTEL, M. J., STAUB, L. P., RODER, C. \& EGGLI, S. High incidence of medication documentation errors in a Swiss university hospital due to the handwritten prescription process. BMC Health Serv Res, 2011; 11, 199.

HEATON, A., WEBB, D. J. \& MAXWELL, S. R. Undergraduate preparation for prescribing: the views of 2413 UK medical students and recent graduates. Br J Clin Pharmacol, 2008; 66, 128-34.

IRSHAID, Y. M., AL-HOMRANY, M. A., HAMDI, A. A., ADJEPON-YAMOAH, K. K. \& MAHFOUZ, A. A. A pharmacoepidemiological study of prescription pattern in outpatient clinics in Southwestern Saudi Arabia. Saudi Med J, 2004; 25, 1864-70.

JAYAWARDENA, S., EISDORFER, J., INDULKAR, S., PAL, S. A., SOORIABALAN, D. \& CUCCO, R. Prescription errors and the impact of computerized prescription order entry system in a communitybased hospital. Am J Ther, 2007; 14, 336-40.

LIEB, K. \& BRANDTONIES, S. A survey of german physicians in private practice about contacts with pharmaceutical sales representatives. Dtsch Arztebl Int, 2010; 107, 392-8.

MAKONNEN, E., YOSEPH, M. \& BERHANE, Y. Quality of prescription at a tertiary care pharmacy in Addis Ababa. Ethiop Med J, 2002; 40, 233-9.

MIRCO, A., CAMPOS, L., FALCAO, F., NUNES, J. S. \& ALEIXO, A. Medication errors in an internal medicine department. Evaluation of a computerized prescription system. Pharm World Sci, $2005 ; 27,351-2$.

OSHIKOYA, K. A. \& OJO, O. I. Medication errors in paediatric outpatient prescriptions of a teaching hospital in Nigeria. Nig $Q$ J Hosp Med, 2007; 17, 74-8.
RAMBHADE, S., CHAKARBORTY, A., SHRIVASTAVA, A., PATIL, U. K. \& RAMBHADE, A. A survey on polypharmacy and use of inappropriate medications. Toxicol Int, 2012; 19, 68-73.

ROSS, S., RYAN, C., DUNCAN, E. M., FRANCIS, J. J., JOHNSTON, M., KER, J. S., LEE, A. J., MACLEOD, M. J., MAXWELL, S., MCKAY, G., MCLAY, J., WEBB, D. J. \& BOND, C. Perceived causes of prescribing errors by junior doctors in hospital inpatients: a study from the PROTECT programme. BMJ Qual Saf, 2013; 22, 97-102.

SILVERIO, M. S. \& LEITE, I. C. Quality of prescriptions in a city of Minas Gerais: a pharmacoepidemiological approach. Rev Assoc Med Bras, 2010; 56, 675-80.

SONDERGAARD, J., VACH, K., KRAGSTRUP, J. \& ANDERSEN, M. Impact of pharmaceutical representative visits on GPs drug preferences. Fam Pract, 2009; 26, 204-9.

TAMUNO, I. \& FADARE, J. O. Drug prescription pattern in a Nigerian tertiary hospital. Tropical Journal of Pharmaceutical Research, 2012; 11, 146-152.

VAN ROSSE, F., MAAT, B., RADEMAKER, C. M., VAN VUGHT, A. J., EGBERTS, A. C. \& BOLLEN, C. W. The effect of computerized physician order entry on medication prescription errors and clinical outcome in pediatric and intensive care: a systematic review. Pediatrics, 2009; 123, 1184-90.

WINSLOW, E. H., NESTOR, V. A., DAVIDOFF, S. K., THOMPSON, P. G. \& BORUM, J. C. Legibility and completeness of physicians' handwritten medication orders. Heart Lung, 1997; 26, 158-64.

YOUSIF, E., AHMED, A. M., ABDALLA, M. E. \& ABDELGADIR, M. A. Deficiencies in medical prescriptions in a Sudanese hospital. East Mediterr Health J, 2006; 12, 915-8.

YOUSIF, M. A., NIZAR, S., ELMUSTAFA, M. O., MUSTAFA, M. I. \& BELLA, M. M.. Investigation of medication prescribing errors in Wad Medani, Gezira, Sudan. Int J Risk Saf Med, 2011; 23, 11-6.

\section{How to cite this article:}

Joseph O. Fadare, Segun Matthew Agboola, Rachel A. Alabi., Quality of Prescriptions in a Tertiary Care Hospital in South-West Nigeria. J App Pharm Sci, 2013; 3 (09): 081-084. 